\title{
Combined Use of Problem-Based Learning and Flipped Learning in Turbomachinery
}

\author{
Juan Ignacio Córcoles, Ángel Martínez-Romero
}

Department of Applied Mechanic, University of Castilla -La Mancha, Albacete, Spain.

\begin{abstract}
Several methodologies are available to promote active learning processes. This is especially important under the creation of the European Higher Education Area, which has contributed to enhance university teaching through the use of new teaching tools. The aim of this paper is to present results about the use of Problem-Based Learning combined with Flipped Learning methodology for teaching turbomachinery, with a group of 50 undergraduate students. This experience was implemented in the Industrial Engineering School at the University of Castilla-La Mancha (Albacete, Spain). The aim of this study was to implement innovative tools to avoid conventional classes at the university. Moreover, it can be useful to increase motivation, because students participate in class, interacting with other students.

Both methodologies resulted in a very positive learning experience, with most of the students (89\%) participating in the task, which is not commonly achieved in a conventional class. The majority of students considered this type of activity to be useful for the subject although they thought it necessary to devote more time to it for the methodology to function properly.
\end{abstract}

Keywords: Problem-based learning; flipped learning; university, turbomachinery. 


\section{Introduction}

Several methodologies are available to promote active learning processes. This is especially important under the creation of the European Higher Education Area, which has contributed to enhance University teaching through the use of new teaching tools. These tools include Problem-Based Learning (PBL) (Bouhuijs, 2011; Labra et al., 2011; Castaño, 2015) and Flipped Learning (FL)(Garza, 2004; Findlay et al., 2004). Problem Based Learning can be defined as an instructional learner-centred approach that empowers learners to conduct research, integrate theory and practice, and apply knowledge and skills to develop a viable solution to a defined problem (Savery, 2006). Flipped Learning is a pedagogical approach that allows teachers to create an interactive learning environment, promoting dynamic activities in class (Pierce and Fox, 2012).

The aim of this paper is to present results on the use of Problem-Based Learning methodology combined with Flipped Learning in the teaching of turbomachinery, with a group of 50 undergraduate students. This experience was implemented in the Industrial Engineering School at the University of Castilla- La Mancha (Albacete, Spain). The aim of using these methodologies was to increase motivation, and provide students with a different way to learn course content, avoiding the deductive approaches used in conventional classes.

\section{Methodology}

\subsection{Proposed Case}

The main case study proposed was based on a previous experience carried out by the authors (Córcoles and Martínez-Romero, 2019), developing Problem-Based Learning methodology, where the students had to solve a problem in class to detect the main deficiencies in an urban water network. Hence, the students had some previous experience in the use of ProblemBased Learning tools but had never used Flipped Learning methodology. In the case mentioned, undergraduates studying turbomachinery have to identify the main problem in a village, the urban water network of which does not guarantee enough pressure and flow rate to the hydrants. To solve this problem, the students have general information about the case, and have to read a text explaining the main problem of the network.

In the proposed case, the urban distribution network consists of $75 \mathrm{~km}$ of pipelines and more than 300 connections, and supplies a population of 2500 inhabitants, which increases by $30 \%$ at different times of the year, when the problem is further aggravated. The network has a regulation-storage tank that supplies water by gravity. The tank is filled with a submersible water pump (located at a distance of $1 \mathrm{~km}$ ) that extracts water from the aquifer. This pump usually works in hours of reduced energy cost, following the electricity tariffs chosen by the local council. 


\subsection{Methodological procedure}

To carry out this PBL activity, students are divided in small groups (approximately 8 students per group). In this task, students ask the teacher, who plays the role of technician and user of the network, questions about the system. After the question session, they have to identify the problem.

In this problem, the students will detect that the pumping system does not work properly, and hence they need to check how the pump is working. To carry this out, a second activity is proposed, based on Flipped Learning, where students, rather than being given a conventional class on pumps, have to obtain the information for themselves.

With this aim, once they have analysed the previously proposed case, the students have to search for information related to a pump characteristic curve (White, 2016). This information is important to understand how a pump works and is needed to solve the proposed problem. In this regard, the students have just a general idea about a pump characteristic curve but have no previous information related to this. Once they have the information, they will be able to understand and resolve the proposed case, which draws on Problem-Based Learning. Thus, using Flipped Learning methodology, the students need to carry out the following tasks:

Search for information on the characteristic curves of a centrifugal pump. Describe the most important aspects of the curves.

Drawing on the results obtained, answer the following question. Can a pump work under different conditions? That is, can a change in water demand in the network modify the flow supplied?

Represent the curve of minimum resistance of an installation in a reference system (coordinate axis) H (m) vs. Q (1/h) and select a pump (motor curve H (m) vs. Q (1/h)).

As additional information, the students can understand better how to determine a pump characteristic curve because they have an installation in the laboratory that reproduces the operation of a pumping system (Fig. 1) as well as devices to measure pressure and flow rate (Fig. 2). 


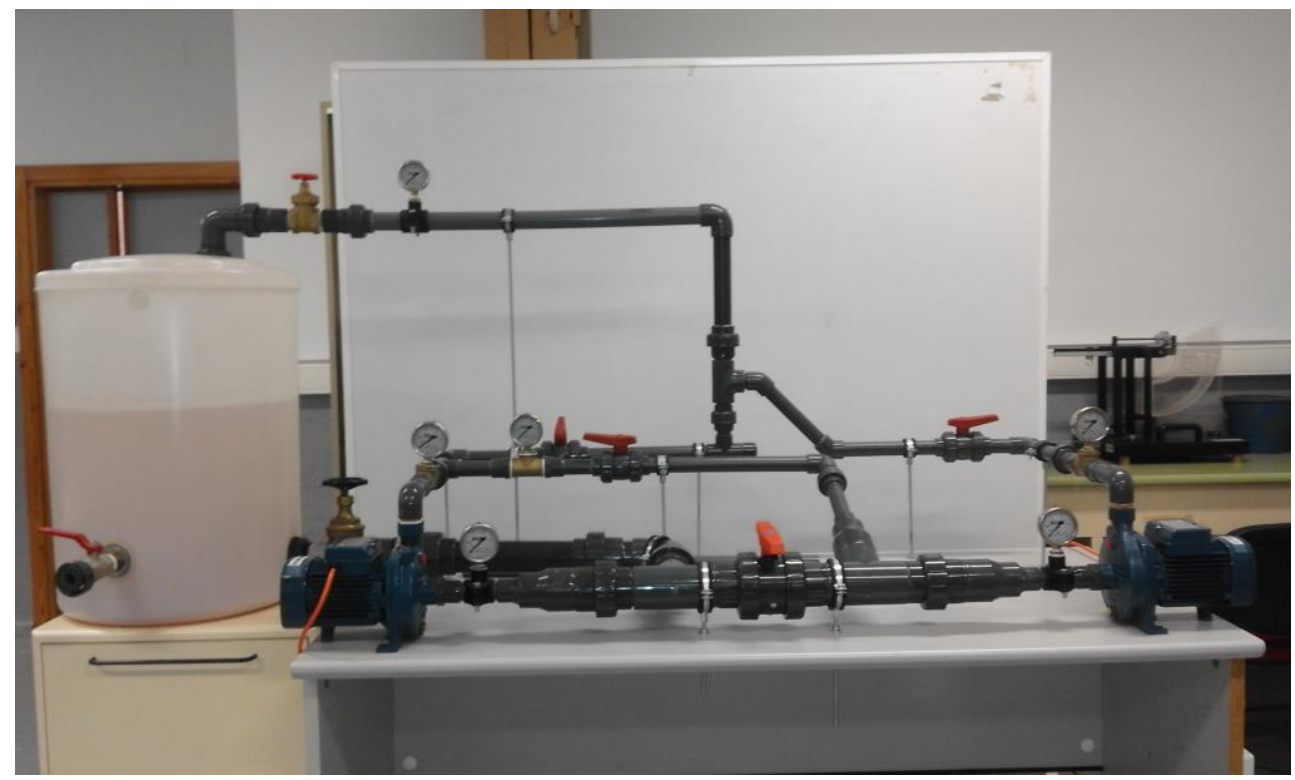

Figure 1. Experimental set-up

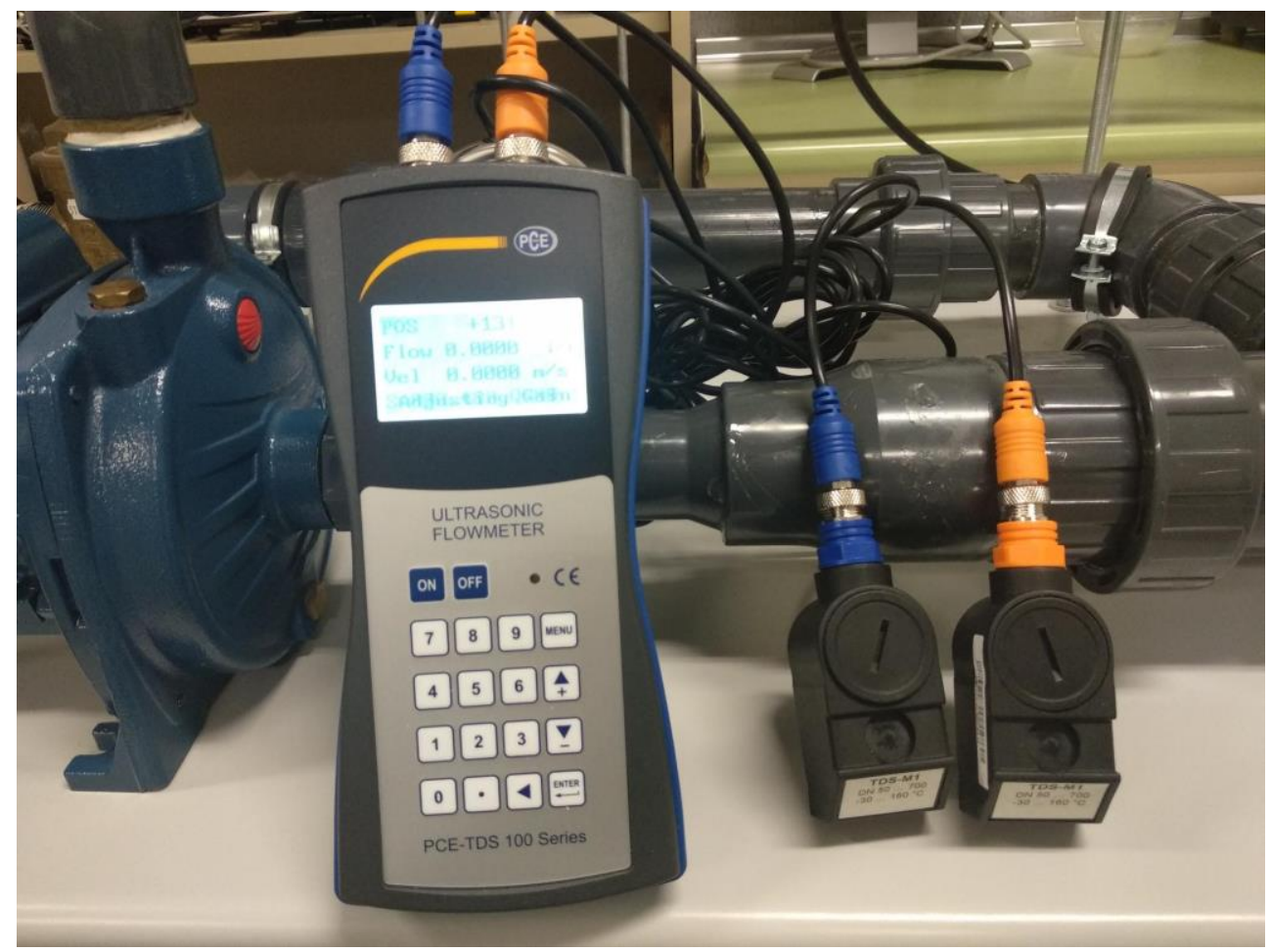

Figure 2. Ultrasound flow meter 
When they finish this activity, as a methodological instrument, the students have to complete a short survey including the following questions:

Table 1. Proposed questions.

\begin{tabular}{|c|c|}
\hline Question & Options \\
\hline \multirow{5}{*}{$\begin{array}{l}\text { 1. How much new knowledge does this } \\
\text { activity provide you with? }\end{array}$} & 1. None \\
\hline & 2. A little \\
\hline & 3. Some \\
\hline & 4. A lot \\
\hline & 5. All the knowledge is new \\
\hline \multirow{5}{*}{$\begin{array}{l}\text { 2. How is content assimilated compared to a } \\
\text { conventional class? }\end{array}$} & 1. The content is not understood \\
\hline & 2. Worse \\
\hline & 3. The same \\
\hline & 4. Better \\
\hline & 5. A lot better \\
\hline \multirow{5}{*}{$\begin{array}{l}\text { 3. How applicable is the activity to the world of } \\
\text { work? }\end{array}$} & 1. Not at all \\
\hline & 2. Not very applicable \\
\hline & 3. Moderately applicable \\
\hline & 4. Reasonably applicable \\
\hline & 5. Very applicable \\
\hline \multirow{5}{*}{$\begin{array}{l}\text { 4. How would you define the difficulty of the } \\
\text { activity? }\end{array}$} & 1. Low \\
\hline & 2. Medium \\
\hline & 3. High \\
\hline & 4. Very high \\
\hline & 5. Impossible \\
\hline \multirow{4}{*}{$\begin{array}{l}\text { 5. Is it interesting to include activities of this type in } \\
\text { the subject? }\end{array}$} & 1. No \\
\hline & $\begin{array}{l}\text { 2. Yes, but devoting less time to } \\
\text { them }\end{array}$ \\
\hline & 3. Yes, but devoting more time \\
\hline & 4. Yes, but devoting a lot of time \\
\hline \multirow[t]{5}{*}{ 6. Indicate to what extent the aims were clear } & 1. Not at all clear \\
\hline & 2. Partly understood \\
\hline & $\begin{array}{l}\text { 3. Partly understood with the } \\
\text { lecturer's help }\end{array}$ \\
\hline & $\begin{array}{l}\text { 4. Completely understood with the } \\
\text { lecturer's help }\end{array}$ \\
\hline & $\begin{array}{l}\text { 4. Completely understood without } \\
\text { the lecturer's help }\end{array}$ \\
\hline
\end{tabular}




\section{Results and Discussion}

The following section presents the results of the experience carried out. It has been divided into 2 sections: 1) ranking of the questions proposed by the professor, and, 2) pupils' responses to the learning and satisfaction surveys.

First of all, it is important to note that $89 \%$ of the students enrolled completed the activity, compared to $79 \%$ who normally attend class.

\subsection{Ranking of the questions proposed by professor}

The activity is assessable, and, as well as the high level of participation (89\%), student engagement was high. The average student grade was 8.34 (out of 10). No student failed. These grades are markedly higher than those achieved by the same students on different tests during the academic year, where the mean score was 6.54 and $28.6 \%$ of students failed (below 5 out of 10$)$.

\subsection{Learning and satisfaction surveys}

In Figure 3, the main results for questions 1 to 6 (Table 1) (related to the evaluation of the activity in the students' training and its importance in the subject) are shown.

In this regard, approximately $97 \%$ of the students considered that the activity provides new knowledge (question 1) and 70\% of them say they understand it better than in a typical class (question 2). In addition, about 97\% find it interesting to include activities of this type in the subject, but more time should be devoted to them (question 5). Only 3\% of students think that the activity is not applicable to real life (question 3) and 30\% that is it not very directly applicable, but is applicable in terms of problem-solving processes. On the other hand, 67\% think that it is really applicable. For most students $(76 \%)$ the activity involves certain difficulty (question 4). The objectives of the activity were clear, as $48 \%$ of the students say that they fully understood the objectives of the activity (question 6), and $42 \%$, although they understood, needed the support of the teacher.

The students rated the activity with a score of 7.6 out of 10 , and $82 \%$ scored 7 or more. Only $3 \%$ rated it below 5 . 

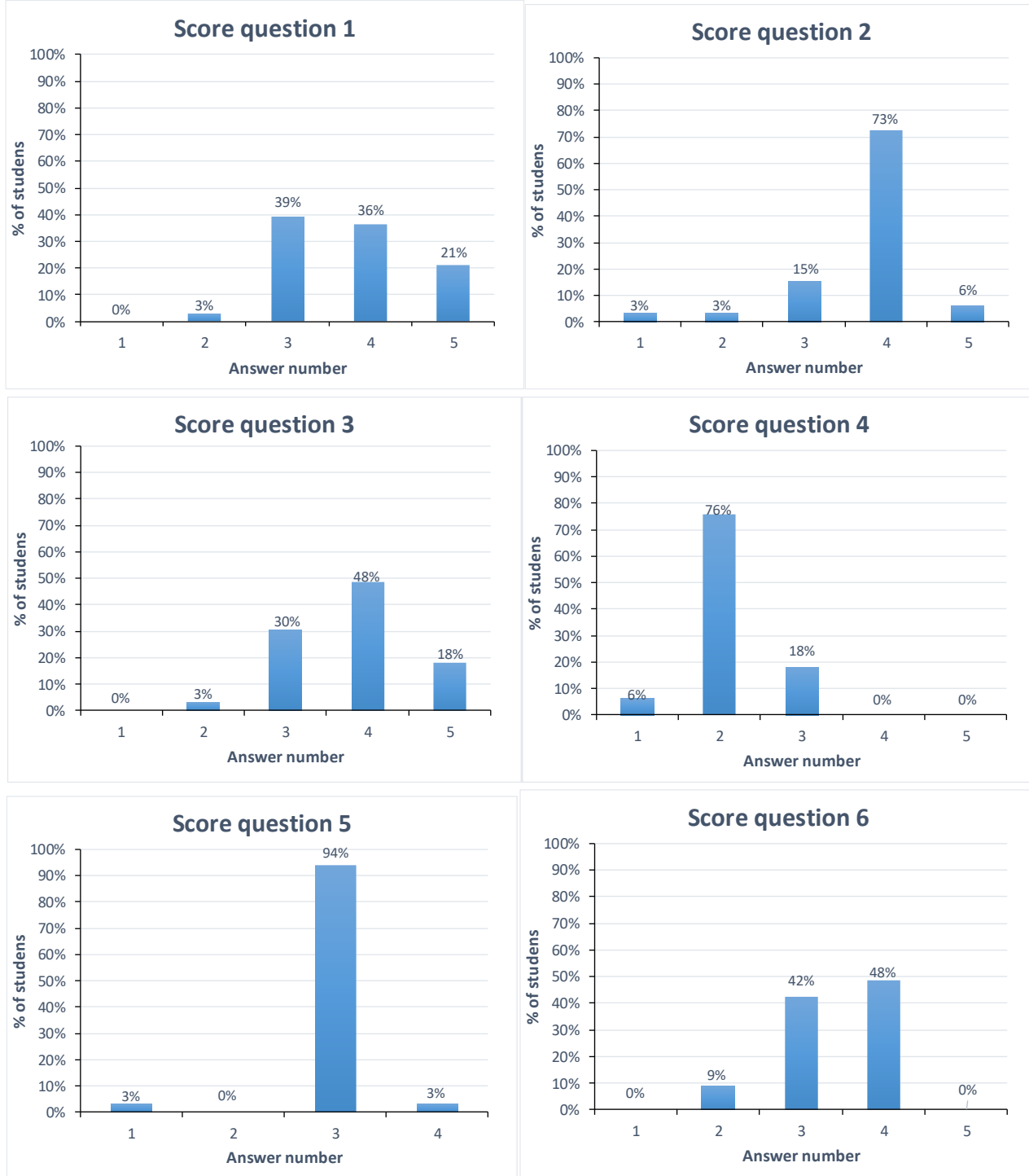

Figure 3. Score distribution for Questions 1 to 6.

\section{Conclusions}

This paper presents a combined study of Problem-Based Learning with Flipped Learning methodologies, the aim of which is to implement innovative tools to avoid conventional classes at university. Moreover, it can be useful to increase motivation, because students participate in class, interacting with other students. 
The majority of students considered this type of activity to be useful in the subject although they think it necessary to devote more time to it for the methodology to function properly.

Both methodologies resulted in a highly positive learning experience, given that most of the students participated in the task, which is not commonly achieved in a conventional class. The main problem of these methodologies is that they are difficult to apply with a large number of students, which can be considered the principal limitation. Our experience suggests that the most noteworthy benefit of these methodologies is the high degree of student motivation, with most participants seeking to find a reasonable answer to the problem.

\section{Acknowledgements}

This work was partially funded by the Industrial Engineering School at Castilla - La Mancha University

\section{References}

Bouhuijs, P.A.J. (2011) Implementing Problem Based Learning: Why is it so hard?, Revista de Docencia Universitaria, 9 (1), 17-24.

Castaño, V. (2015). El método del aprendizaje basado en problemas como una herramienta para la enseñanza de las matemáticas. Revista Iberoamericana para la investigación y el Desarrollo Educativo, 6 (11).

Córcoles, J.I., \& Martínez-Romero, A. (2019). Introduction to the method of problem based learning for teaching Fluid Mechanics. 13th International Technology, Education and Development Conference (INTED), 2577-2584. I.S.B.N: 978-84-09-08619-1

Findlay, S., \& Mombourquette, P. (2014). Evaluation of a flipped classroom in an undergraduate business course. Business Education and Acreditacion, 6 (1), 63-71.

Garza, S.A. (2004). The Flipped Classroom Teaching Model and its Use for Information Literacy Instruction, Communications in Information Literacy, 8 (1), 7-22.

Labra, P., Kokaly, E. , Iturra, C., Convha, A., Sasso, P., \& Vergara, M (2011). El enfoque $\mathrm{ABP}$ en la formacion inicial docente de la Universidad de Atacama: el impacto en el quehacer docente. Estudios Pedagógicos XXXVII, 1, 167-185.

Pierce, R., \& Fox, J. (2012). Vodcasts and active-learning exercises in a "flipped classroom" model of a renal pharmacotherapy module. American Journal of Pharmaceutical Education, 76 (10), 1-5.

Savery, J.R. (2006). Overview of Problem-based Learning: Definitions and Distinctions, Interdisciplinary Journal of Problem-Based Learning, 1 (1), 9-20.

White, F. (2016). Fluid Mechanics. New York: Mc-Graw-Hill. 